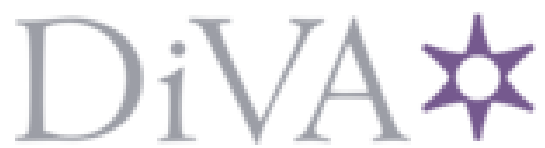

http://www.diva-portal.org

This is the published version of a chapter published in Core values and the expeditionary mindset: armed forces in metamorphosis.

Citation for the original published chapter:

Fürst, H., Kümmel, G. (2011)

Emotions: A Neglected Dimension of the Expeditionary Mindset

In: Henrik Fürst \& Gerhard Kümmel (ed.), Core values and the expeditionary mindset: armed forces in metamorphosis (pp. 215-223). Baden-Baden: Nomos Verlagsgesellschaft

N.B. When citing this work, cite the original published chapter.

Permanent link to this version:

http://urn.kb.se/resolve?urn=urn:nbn:se:uu:diva-182368 


\title{
Emotions: A Neglected Dimension of the Expeditionary Mindset
}

\author{
Henrik Fürst \& Gerhard Kümmel
}

\section{Core Values and the Expeditionary Mindset: Concepts under Construction}

Core Values and the Expeditionary Mindset - this conference topic proved to be highly complex and multi-faceted. The contributions to this book reflect this very much as they offer various approaches to and perspectives and dimensions of the theme. While some conceptually focus primarily on the expeditionary mindset (Shields, Winslow), others put core values at center-stage in their contribution (Kasher, Sørensen, Tripodi/ Connelley). Still others reflect on all this with an eye on leadership and officer education (Ben-Ari, Mäkinen) or approach the issues of core values and expeditionary mindset from a different conceptual angle, such as national interest (Ford), identity (Kümmel) or, quite similarly, soldierly role perceptions as homeland defender, warrior and state employee (Haaland). To various extents all the authors provide insights into various national armed forces amidst the process of turning expeditionary and sometimes this national lens is even the predominant one (Ford, Haaland, Sørensen, Ong), yet with concentration on different themes such as multinational military cooperation (Kenkel) or the pros and cons of differrent military recruiting systems, in terms of the requirements of expeditionary operations, with a juxtaposition of armed forces based on conscription versus an all-volunteer force (Klein).

All contributors, however, agree that the armed forces, for various reasons, are nowadays in metamorphosis which also documents the mainstream of the discourse where only few would argue that little or nothing has changed with regard to the military. The contributors also basically agree that modern armed forces, obviously with national variations and to differing degrees as the case studies in the second part of the book indicate, are heading to some form of expeditionary-ness. With regard to this, the expeditionary mindset, it seems to us that most if not all contributors could agree upon expeditionary requirements (retrieved from the contributions to this book) such as: the moral, humanitarian and/or cosmopolitan conduct of military operations; the mental preparedness to deploy on short notice; the capability for conducting network-centric warfare; knowledge of the local culture; empathy; negotiation skills; some degree of critical thinking and reflectivity to help manage changing, ambivalent and ambiguous environments; improvising skills; and persuasion, or the ability to cooperate and build relationships with a multitude of different military as well as different civilian actors which follow different codes of conduct, different organizational principles and different logics or mental maps.

In essence, then, the expeditionary mindset resembles a practical concept to capture the changes occurring in military services directed towards expeditionary operations. It is about the capabilities for adapting to a changing or what some may term 'postmodern' world where there is constant flux. The expeditionary mindset is also about human creativity and an orientation towards ad-hoc effective and pragmatic problem-solving in difficult situations as they arise. The expeditionary mindset is in fact a construct geared towards some form of check-list or how-to-do-list for armed forces that want to handle expeditionary operations successfully. The concept is thus very flexible and practicable 
since it is about the capabilities of both individuals and organizations to adapt to changing situations.

With regard to core values, consensus among the authors of this book seems to be less widespread. In an Aristotelian sense, core values guide behavior and are rigid, fixed, static and not subject to rapid change. Shields, e.g., conceives core values in precisely this manner when she argues in her chapter that warrior and military core values are quite universal and transcend time and place. Yet, she also hypothesizes that the military metamorphosis into expeditionary armed forces may not leave military core values untouched. The solutions presented in this volume differ and, at times, do not seem to be fully convincing to us, but will most likely stimulate further research: Tripodi/Connelley adhere to the notion of core values being fixed values and identify, by resorting to the United States Marines Corps' approach, honor, courage and commitment as these core values. They go on to argue that these core values in fact need not change in order to meet the requirements for expeditionary operations as these core values already contain, cover and include the values deemed necessary for expeditionary missions. Kasher, in turn, tries to solve this problem by distinguishing fixed core values, such as courage and comradeship, and transformed core values such as responsibility, professionalism and discipline to which Kasher attaches some new facets of meaning thus transcending and extending their classical, traditional meaning. He also cites human dignity protection, sanctity of human life and restraint of force as such transformed core values. Next, Sørensen defines what he calls actual core values and identifies, in this order of importance, the group, the individual soldier, the war and the local community as actual core values. From this he distinguishes needed core values, which are the same as the actual core values, but in reverse order placing the local community on top of the list. Ford adds to this peace, order and good government which he identifies as (Canadian) national interests perceived and equated by him with core values. Eventually, Kümmel somewhat evades the problematique of core values and of defining what a core value is and is not by turning to soldierly identity which he frames in a dynamic three-dimensional model that is by itself contrary to the static notion of core values. A similar route is taken by Haaland who identifies the homeland defender, the warrior and the state employee as different types of soldierly role perceptions. In what follows, then, we will also leave aside the delicate issue of core values and instead concentrate on the expeditionary mindset by sketching what, in our view, is still missing in the discourse on expeditionary-ness.

\section{The Emotional Turn of the Discourse on the Expeditionary Mindset}

Our starting point is the assumption that expeditionary military operations are characterized by an enormous complexity as they may, sometimes simultaneously so to speak, entail war-fighting, peace-making, peace-enforcement, de-escalation, peace-keeping, and post-conflict peace- and state-building. Managing conflicts has proven to be immensely difficult and challenging, sometimes even messy in the recent past, because neat distinctions between different phases of the conflict, e.g. a line from a peaceenforcement phase to a peace-keeping phase to a peace-building phase can rarely be made. Instead, the situation may change any time, implying that the phases and stages may intermingle with one another, moving forwards and backwards and sometimes even sideways. This is precisely the reason why, in this book, there was talk about the 
necessity of having hyphenated roles for soldiers and the military (Ben-Ari) and about the shift to a hybrid military and the hybrid soldier (Kümmel). This being the case, the basic trait of expeditionary missions can be said to be uncertainty which may generate fear (see Bauman 2010).

If this analysis proves to be correct, the management of uncertainty and fear through the organization becomes central to the expeditionary mindset and thus for the conduct of expeditionary operations. Such management then requires to instill confidence and trust into the organization and thus the purposeful management of emotions as part of the organization's efforts for coordinated action. This rests with the proposition that "emotions pervade virtually every aspect of human experience and all social relations" (Turner/Stets 2005: 1), and thus also organizations, a perspective that has hitherto been left untouched in the existing literature on the expeditionary mindset (see also Fürst 2009) just as much as there has been a general lack of interest in emotions within sociology until quite recently (Barbalet 1998: 82). Bringing in this view therefore represents what we may call the emotional turn of the expeditionary mindset discourse.

The concept of expeditionary mindset has a remarkable strong emphasis on preparing mental readiness for action. The 'mind' is 'set' on preparing and carrying out expeditionary missions. The readiness for action is then strongly associated with a cognitivist paradigm centered on the mind and leaves out the importance of emotion, as it has become associated with the body, as bases for preparation and carrying out action. ${ }^{1}$ The expeditionary mindset was first mentioned in the US Marines 1940 Small Wars Manual (Shields). Interestingly, this happened at the same time as sociology, and other social sciences, became interested in the cognitive bases of social action (see Barbalet 1998: 16-20). Our approach here is to transcend the dichotomy that is often implied when speaking of mind and body and develop an integrative perspective instead, while, at the same time, not reducing or confusing emotions with mind or body.

The expeditionary mindset will be discussed in relation to the purposeful organizational scripting of emotions, which emulates Zurcher's (1985, see also 1982) notion of organizational scripting and Hochschild's (1983) notion of emotion management. The hypothesis we advance here states that such organizational scripting of emotions is a prerequisite to manage uncertainty and fear and needs to focus on confidence, as the opposite of fear, because confidence and trust are conducive to an action-oriented outlook (Barbalet 1998). Confidence is to be involved on the level of the organization. Organizational learning through organizing emotional scripts may be a way of accomplishing and establishing confidence as a shared emotion. We thus follow a social constructivist approach towards explicating how emotions are molded, structured and given meaning in emerging social situations (see Adler/Adler/Fontana 1987). We argue that emotions are a crucial aspect in the (social) formation of an expeditionary mindset and particularly stress the pre-deployment phase as the ideal point in time to purposefully and collectively orient the organization's members towards an expeditionary mission by creating a shared climate of confidence. ${ }^{2}$ This is done by managing fear through organ-

1 Mäkinen, in his chapter, points out that there has been a lack of interest in the body when looking at the expeditionary mindset.

2 We have previously mentioned the hyphenated roles and the constraints of moving between different situations and demands in during mission as something that needs to be well organized. Here the emphasis is on the pre-deployment phase and the uncertainty of always being ready to go anywhere in the world within short notice. 
izational scripting, thereby enabling the individual to live with uncertainty, contingency, ambivalence and ambiguity. The model outlined here can be considered an initial stepping-stone in reflecting on emotions as an organizational feature of core relevance for expeditionary missions and the expeditionary mindset. We will start with Hochschild's (1983) view on how emotions are managed in labor and move on to Zurcher's (1985) approach to emotions and organization and explicate their usefulness regarding the expeditionary mindset.

\subsection{Hochschild: Managing Emotions and Doing Emotional Labor - The Air Hostess}

Hochschild (1983) conducted a threefold study published in her book The Managed Heart: Commercialization of Human Feelings. The first one is a student survey in which students were asked to describe a situation when they felt a deep emotion. This represents private accounts of feelings. The second one which was ethnographic in character was a qualitative study based on interviews with air hostesses and on participant observation in activities of air hostesses. This Hochschild takes as the public front of the emotional system. Third and lastly, she did a minor study on bill collectors which she considered to be the public back of the emotional system.

Of particular interest to our topic is the study of the air hostesses. Her study mainly takes a dramaturgical symbolic interactionist perspective that focuses on the social guidelines of emotion. Hochschild (1983: 16) concludes that the air hostesses' emotions are set by a standard of the company and sold as a commodity. 'Emotion work', something that previously had been acted out in private, is something that has become 'public' and is sold and bought on a certain market where the seller is expected to sell, in this case, his/her compassion and manage inappropriate emotions (Hochschild 1983: 118). To show a set of particular emotions is expected in the air hostess situation and is thus a genuine part of work. Emotions shown to the clients and expected from them may be distinguished according to the level of distance to the emotion displayed. Here, Hochschild (1983: 33) differentiates, by turning to the theater theorist Konstantin Stanislavski, between 'surface acting' and 'deep acting'. Surface acting, i.e. what 'outwardly' appears in front of others, is an act of pretending to feel what is not felt, but still being aware that one is pretending (Hochschild 1983: 33-38). Deep acting, by contrast, is when a person is fully into an act and displays emotions 'as if' they were happening for 'real'; the emotions are expressed spontaneously and the person is deceived to believe that it is the real thing (Hochschild 1983: 33-42).

Some sort of a process of learning to act out the appropriate emotion for a reoccurring situation is certainly involved in order to be able to act in such manners. To some extent, it seems that Hochschild is inclined to think in terms of an 'authentic' self (the private self) and a 'non-authentic' self (the public self) which explains her conceptualization of emotional labor and emotion management as something negative, resembling some sort of social technology. Yet, we maintain that emotion management needs to be understood as something essential and unavoidable which, at the same time, is still something that may have positive benefits for both the individual and the organization (see Wharton 1993). 


\subsection{Zurcher: The Staged Setting and Emotions as Part of Organizational Scripts - The War Game}

Zurcher (1985) has also taken a dramaturgical symbolic interactionist stance in his study of a naval reservist war game which is based on participant observation as well as informal interviews. At the time of the study the naval reservists were usually doing a war game on one weekend a month. The war exercise Zurcher chose took place on a small island. The participants were to have a combat-appropriate behavior and a gung-ho emotional expression in the exercise and to act 'as if' the game was real thing. Zurcher describes the situation in dramaturgical metaphors: uniforms were considered costumes, personal grooming was demeanor and the commanders were the directors (Zurcher 1985: 194). Since this was a war game these metaphors are highly usable because the participants were all part of a staged setting; they were actors. Nevertheless, we propose that these metaphors can also be used to analyze and understand non-staged settings of war-like situations.

Zurcher (1985) suggests that emotions are scripted in a structural and interactional context (see also Hochschild 1983) and shows that the script of the situation is continually disrupted and re-negotiated in the course of events that include a constant reformation of the war game context. ${ }^{3}$ Emotions, then, are seen as related to role behavior, implying that emotions arise in a specific context, or situation, and therefore are interpretations of social interaction (Zurcher 1985: 191). As a consequence, the expression of an emotion is something dramaturgical; we act within a role and in relation to a script. So, the script is the manuscript that guides, but not completely determines action which leaves some leeway of action for creatively adapting and negotiating these scripts. The war game study is proof of this because the participants of the war game did actually enact, modify or negate the organizational script. Negating the script occurred under great stress and exhaustion; in these situations the participants privatized their emotions, made them an individual matter and the expressions of emotions were sparsely visible (Zurcher 1985: 199). Organizational scripts include gaps and inconsistencies, the scripts cannot anticipate all situations (Zurcher 1985: 201). The meaning of the organizational script is determined by the participants "in the context of their own inclinations, their interaction with other members, the nature of the immediate situation, and the expectations of the organization" (Zurcher 1985: 201). Modifying the script entails ad-hoc alterations of the script such as new things coming in or situations that emerge during action, e.g., a fire or rain.

One example of emotional scripting is the role officers play during a training camp of reservists. "During the drills immediately before the war game, supervisors must ensure readiness of their units for logistical aspects of the exercise. They also must urge the expression of emotion appropriate in the culture and ideology of the military. The status of supervisors in the organizational hierarchy empowered them to define the emo-

3 This emergent form of ordering is similar to the notion of negotiated order. A negotiated order is an outcome of negotiation of various actors with different possibilities to change the nature of that organization and is in constant and dynamical change through the interaction between actors and organization (Strauss 1978). In this view an organizational script could also be seen as an outcome of negotiation and is thus partly creatively emergents. In contrast, Hochschild (1983) would state that there are social guidelines and that feeling rules govern human action. 
tions expected." (Zurcher 1985: 194) ${ }^{4}$ We may infer there from that if a script is to gain force, there must be effective leadership instilling the appropriate emotions.

Zurcher (1985: 192) views emotions as "a socially constructed pattern of sensations, expressed gestures, and cultural meanings organized around a relation to a social object, usually another person". Emotions are thus relational and dependent on an object or another; when there is a change in the relationship, emotions change as well (Barbalet 1998: 180). This implies that emotions are something that is learned through changing the conditions for actions. This resonates with Damasio's (1994) neuroscientist differentiation between primary and secondary emotions ${ }^{5}$ and especially his conception of secondary emotions because while he conceives primary emotions as something we have since birth, secondary emotions are something we learn.

According to Zurcher, emotions communicate our relationship towards ourselves and the meaning we give to the world around us. Emotions also guide our conscious thoughts (Damasio 1994). Another person's relation towards an object or another person may be signaled through emotions and has then interactional consequences, since meaning is given through emotions. However, the organizational script must continually be reconstituted in action. Emotional scripts need to have 'force', i.e. some power and persuasiveness in order for the participants to be enmeshed in it (Zurcher 1985: 195). Scripts are then to be effective means of organizing social relationships between individuals, which also applies to the military facing expeditionary operations. So the expeditionary forces are in need of the organizational scripting of emotions in order to be able to prepare for uncertainty; also expeditionary forces should have scripts at hand that enable them for to ad-hoc scripting that occurs before, during and after expeditionary operations.

\subsection{Emotion Management versus Organizational Scripting}

The organizational scripting of emotions is not to be confused with the terms emotional labor or emotion management as a way of letting workers "mentally detach themselves" from their actual selves in order to work with their emotions as an asset (Hochschild 1983: 17). Emotional labor, and thus emotion management, is more precisely defined as the labor that "requires one to induce or suppress feeling in order to sustain the outward countenance that produces the proper state of mind in others - in this case, the sense of being cared for in a convivial and safe place. This kind of labor calls for a coordination of mind and feeling, and it sometimes draws on a source of self that we honor as deep and integral to our individuality" (Hochschild 1983: 7).

By contrast, organizational scripting is a reciprocal process that creates an emotional climate that is in line with expectations of possible outcomes of present and future interaction. The organizational scripting of emotions is not entirely determining behavior; rather it is handled as a guideline for preferable action. In the preparation for action the organizational script should not suppress, but orient the person towards cer-

4 Zurcher $(1982$; 1985) differentiates between emotional expectancy, emotional readiness and emotional performance. In this process there are expectations of upcoming emotional states, the actor becomes prepared. The supervisors make the actor ready for an intended action and thus make them ready to perform an emotion. The performance of the emotions is then the expected outcome of this process.

5 This is, however, a common distinction made (see Turner/Stets 2005). 
tain emotions that are useful in handling future situations. ${ }^{6}$ Organizational scripts are more of a blueprint of preferable action that should be carried out to create a climate of shared emotions. Some sort of competence in emotion may, as is important in the case of expeditionary missions, also be oriented towards the interaction with the local community which is of crucial importance because "we infer other people's viewpoints from how they display feeling" (Hochschild 1983: 32). Indeed, the expeditionary soldier needs to be good in interpreting the emotions of the other, not only with regard to the local populace because the interaction within the group, the unit, or the broader military organization is of prime importance also. This problem is mapped out by Kramer (2007). Kramer states that military organizations should organize doubt in order to reflect on their practice, in order to be able to make sound decisions during complex and changing situations.

\subsection{Emotional Climate, Organizational Scripting and Confidence}

To be able to alter the script in an ad-hoc fashion is of crucial importance for an expeditionary mindset that needs to be flexible and modular. Scripting flexibility as an activity is much required: (1) for preparing for contingencies in future interaction (before an expeditionary mission); (2) for handling contingencies in the theater (during an expeditionary mission); and (3) when leaving the theater (after an expeditionary mission). Ideally, such scripting entails displaying emotions in the group and produces an emotional climate which, in turn, is a basis for establishing group cohesion (Zurcher 1985; Barbalet 1998: 57). Emotional climates may be defined as "sets of emotions or feelings which are not only shared by groups of individuals implicated in the formation and maintenance of political and social identities and collective behaviour. Emotional climate therefore includes emotional tones and patterns which differentiate social groups or categories by virtue of the fact that they are shared by their members and unlikely to be shared with non-members" (Barbalet 1998: 159). The emotional climate is something that affects both the individual actor and collective action and thus provides a link between the micro- and macro-level of society and sets apart the group from other formations: "Indeed, the content of emotional climates not only identifies a subject's socioemotional milieu, but will also point or oriented the subject against, or toward, those outside that milieu to whom these emotion may be directed" (Barbalet 1998: 159). One may then expect that this socio-emotional milieu will be put to the test when missions are carried out and new actors such as the local populace, civil-society actors and other military units are brought into an already existing emotional climate. Such situations must be purposefully prepared for and organized.

Following the pragmatist William James, emotion "both directs action to the future, and constructs the resources which action draws upon through the emotional apprehension of the past" (Barbalet 1998: 186). Our thrust here is that confidence/trust as an emotion is conducive to the operations of an expeditionary force. Confidence can be defined as "bringing a possible future into the present, providing a sense of certainty to

6 This should not be considered as equivalent to Hochschild's term 'feeling rules' which are social guidelines which people come to adapt to through emotion management and emotional labor. Hochschild (1983: 189) defines feeling rules as "standards used in emotional conversation to determine what is rightly owed and owing in the currency of feeling. Through them, we tell what is 'due' in each relation, each role. We pay tribute to each other in the currency of the managing act". 
what is essentially unknowable, so that assured action with regard to it may be engaged" (Barbalet 1998: 88). In the respect that the emotion of confidence brings in a possible future into the present, all action is made dependent on confidence in order to be carried out (Barbalet 1998: 82-83). In this use confidence is not about the judgment of a certain future but about the willingness to act by bringing in a possible future into the present.

The expeditionary-oriented organization should consider how to instill an emotional climate of confidence in the preparation for expeditionary missions. Organizational scripts and emotional climate need to have some power/persuasiveness/force and the emotions shared should lead to cohesion and preferable actions. Confidence may very well work in this direction and is juxtaposed to anxiety which is a fearful anticipation of the future (Barbalet 1998: 90); confidence simply makes people ready to act, and this is sorely needed within the expeditionary mindset.

\section{Conclusion}

The war game described above surely is a staged setting, in some sense an exercise before the 'premiere' of an actual war situation. Scripts are in fact expectations of actions that the actors in a war situation, or in preparation for war situation, need to interpret. If "the expression of emotion in a situated context evolves from expectations for expression, to readiness for expression, to specific emotional performances" (Zurcher 1985: 191), the actor then performs an action or an emotion as expected. This also needs to be done during an actual situation that is neither game nor drill. The expeditionary mindset is far from mechanical and places prime importance on developing and using reflective, critical thinking skills. The organizational script should be creatively adapted to the emerging situations and benefit both individuals and organizations. Confidence that has a direction towards the future can make socially desirable action possible by being organized and acted out under appropriate conditions.

This discussion, in turn, brings us back, interestingly enough, to core values. As outlined above, confidence is seen as essential for an expeditionary military organization in preparation for deployments and missions abroad. In fact, confidence may then be considered a valued asset - or core value - of an expeditionary organization. Emotional scripting is, in fact, a way of training and educating the actors of the military organization, which can involve confidence. However, much work needs to be done with regard to the empirical nature of how emotional scripting works in practice and which emotions under which situations are necessary. One may also look at how effective the organizational scripting is and what kind of resistance such scripting may generate amongst the actors of the organization. The organizational scripting of emotions is a tool, a guideline for action that is not bullet-proof, but may lead to desired results for both the actors and the organization oriented towards expeditionary missions. That is why the emotional turn of the discourse on the expeditionary mindset is promising. 


\section{4. $\quad$ References}

Adler, Peter/Adler, Patricia/Fontana, Andrea (1987): Everyday Life Sociology. In: Annual Review of Sociology, 13, 217-235.

Barbalet, Jack (1998): Emotion, Social Theory, and Social Structure: A Macrosociological Approach. Cambridge: Cambridge University Press.

Bauman, Zygmunt (2010): Liquid Times: Living in an Age of Uncertainty. Cambridge: Polity Press.

Damasio, Antonio (1994): Descartes' Error: Emotion, Reason, and the Human Brain. New York, NY: G. P. Putnam.

Fürst, Henrik (2009): Grundvärderingar, expeditionärt tänkande och expeditionär förmåga. In: Abrahamsson, Bengt: Krigarrollen och 'core values' i utlandsstyrkan (FHS XF 1284/2009: 02).

Hochschild, Arlie Russell (1983): The Managed Heart: Commercialization of Human Feeling. Berkeley, CA: University of California Press.

Kramer, Eric-Hans (2007): Organizing Doubt: Grounded Theory, Army Units and Dealing with Dynamic Complexity. Malmö: Liber.

Strauss, Anselm (1978): Negotiations: Varieties, Contexts, Processes, and Social Order. San Francisco: Jossey-Bass.

Turner, Bryan S. (Ed.) (2009): The New Blackwell Companion to Social Theory. London: Wiley - Blackwell.

Turner, Jonathan/Stets, Jan (2005): The Sociology of Emotions. New York, NY: Cambridge University Press.

Wharton, Amy (1993): The Affective Consequences of Service Work: Managing Emotions on the Job. In: Work and Occupations, 20: 2, 205-232.

Zurcher, Louis (1982): The Staging of Emotion: A Dramaturgical Analysis. In: Symbolic Interaction, 5: 1, 1-22.

Zurcher, Louis (1985): The War Game: Organizational Scripting and the Expression of Emotion. In: Symbolic Interaction, 8: 2, 191-206. 